\title{
Physiochemical, molecular docking, and pharmacokinetic studies of Naproxen and its modified derivatives based on DFT
}

\author{
Moniruzzaman ${ }^{1, *}$, Mohammed Jabedul Hoque ${ }^{2}$ \\ ${ }^{1}$ Department of Applied Chemistry and Biochemical Engineering, Shizuoka University, 3-5-1, Johoku, \\ Hamamatsu, 432-8011, Japan \\ ${ }^{2}$ Faculty of Engineering, Department of Optoelectronics and Nanostructure Science, Shizuoka \\ University, 3-5-1, Johoku, Hamamatsu, 432-8011, Japan
}

\begin{abstract}
:
Naproxen $(\mathrm{N})$ is a member of nonsteroidal anti-inflammation drug and widely used as an analgesic, antipyretic, and anti-inflammation agent. In this investigation, the inherent stability and biochemical interaction of Naproxen and its related molecules have been studied. Density functional theory (DFT) with B3LYP/ 6-31G (d, p) has been employed to optimize the structures. Frontier molecular orbital features (HOMO-LUMO gap, hardness, softness), dipole moment, electrostatic potential and thermodynamic properties (electronic energy, enthalpy, Gibb's free energy) of these optimized drugs are investigated. Molecular docking has been performed against prostaglandin $\mathrm{H} 2(\mathrm{PGH} 2)$ synthase protein $5 \mathrm{~F} 19$ to search the binding affinity and mode(s) of all compounds. It is found that, all compounds are thermodynamically stable; some of them are chemically more reactive and show better binding affinity than the parent drug. ADMET calculations predict the improved pharmacokinetic properties of all compounds. Finally, this study can be helpful for the design of new analgesic, antipyretic drug.
\end{abstract}

Keywords: Naproxen, Density functional theory, Molecular docking, Pharmacokinetics

\section{Introduction}

Naproxen is a nonsteroidal anti-inflammatory drug (NSAID) having naphthalene backbone has been widely used as anti-inflammatory drug with regarding analgesic and antipyretic activities [1], [2]. It can inhibit the prostaglandin synthesis by blocking cyclooxygenase (COX) [3]. It has some demerits depending on the type and nature of unusual physical condition and on the limit of dose. Overdose and long term dose can cause of gastrointestinal [4] and cardiovascular diseases [5], [6]. It has in vivo selectivity upon human cyclooxygenase (COX) enzyme through inhibition of COX-2 whereas inhibition of COX-1 underwent unwanted occurrence on gastrointestinaltract causes ulceration and perforation of the mucosa layer [7]. COX selectivity depends upon dose differentiation as well as concentration of drug. Each of the substituent groups is important for site selective localization on COX [8]. Properly substitution on methoxy site, leading the direction of selectivity towards COX-2 relative to Naproxen [2]. In order to investigate selectivity upon COX-2-COX-1, focusing on rational derivatization could be the alternative strategy with regarding computational array. Apart from that, naproxen also a potent source of pharmaceutical water pollutant since of their extensive uses [9]. Further, pharmaceuticals discharges in to the sewage water and human excreta expose ecotoxicological effects. Moreover, naproxen under certain conditions underwent photo degradation show photoxicity in vivo [10]. Recently, it has been seen the trait of modifying drugs using halogens and alkyl group play important role in improving drug performance. Drug modification is another alternative way to search better agent, which can increase the selective action of drug and reduce the side effect [11].

In this study, attempts have been taken to optimize some modified derivatives of Naproxen to investigate their biochemical behaviour on the basis of quantum mechanical approach. The free energy, electronic energy, enthalpy, dipole moment, electrostatic potential, HOMO-LUMO gap, 
hardness, softness, and atomic partial charge have been calculated. Molecular docking and nonbonding calculation have been performed to understand the binding affinity, mode(s) and interaction between drugs and the amino acid residues of human prostaglandin synthase protein (5F19). Some of the analogues show better thermal stability, chemical reactivity, binding affinity, nonbonding interactions, and improved pharmacokinetics properties than the parent drug, which can promote more potential analgesic activity.

\section{Methods and Computational Details}

2.1. Optimization of ligands using DFT Quantum mechanical (QM) methods has greater attention on calculation of thermodynamic properties, molecular orbital features, dipole moment, atomic partial charge, molecular electrostatic potential and as well as interpretation of different types of interactions [12]. Initial geometry of Naproxen $(\mathrm{N})$ was taken from the online structure database named ChemSpider [13]. Molecular geometry optimization and further modification of all drugs carried out using Gaussian 09 program [14]. All the drugs were optimized using density functional theory (DFT) employing Becke's (B) [15] three-parameter hybrid model, Lee, Yang and Parr's (LYP) correlation functional [16] under Pople's 6$31 \mathrm{G}(\mathrm{d}, \mathrm{p})$ basis set which has amply been proven to give very good ground state geometries [17]. Initial optimization of all compounds was performed in the gas phase. Dipole moment, electronic energy, enthalpy, free energy, electrostatic potential and atomic partial charge are calculated for all the compounds.

\begin{tabular}{cccc}
\cline { 2 - 3 } & $\mathrm{Name}$ & $\mathrm{X}$ & $\mathrm{Y}$ \\
\cline { 2 - 4 } $\mathrm{N}$ & $-\mathrm{CH}_{3}$ & $-\mathrm{CH}_{3}$ \\
$\mathrm{~N} 1$ & $-\mathrm{OCH}_{3}$ & $-\mathrm{CH}_{3}$ \\
$\mathrm{~N} 2$ & $-\mathrm{OCH}_{2} \mathrm{CH}_{3}$ & $-\mathrm{CH}_{3}$ \\
$\mathrm{~N} 3$ & $-\mathrm{CF}_{3}$ & $-\mathrm{CH}_{3}$ \\
$\mathrm{~N} 4$ & $-\mathrm{OCH}_{3}$ & $-\mathrm{H}$ \\
$\mathrm{N} 5$ & $-\mathrm{CH}_{3}$ & $-\mathrm{CH}_{2} \mathrm{CH}_{3}$ \\
$\mathrm{~N} 6$ & $-\mathrm{CH}_{3}$ & $-\mathrm{H}$ \\
$\mathrm{N} 7$ & $-\mathrm{F}$ & $-\mathrm{CH}_{3}$ \\
\hline
\end{tabular}

Fig.1 Chemical structures of Naproxen (N) and its modified analogues

Frontier molecular orbital features HOMO (highest occupied molecular orbital), LUMO (lowest unoccupied molecular orbital) were calculated at the same level of theory. For each of the drugs, hardness $(\eta)$, and softness (S), were calculated from the energies of frontier HOMO and LUMO as reported [18] considering Parr and Pearson interpretation [19]-[20] of DFT and Koopmans theorem [21] on the correlation of ionization potential $(I)$ and electron affinities $(E)$ with HOMO and LUMO energy $(\varepsilon)$. Hardness $(\eta)$, and softness (S) are calculated by using the following equations;

$$
\eta=[\varepsilon L U M O-\varepsilon H O M O] / 2 ; S=1 / \eta
$$

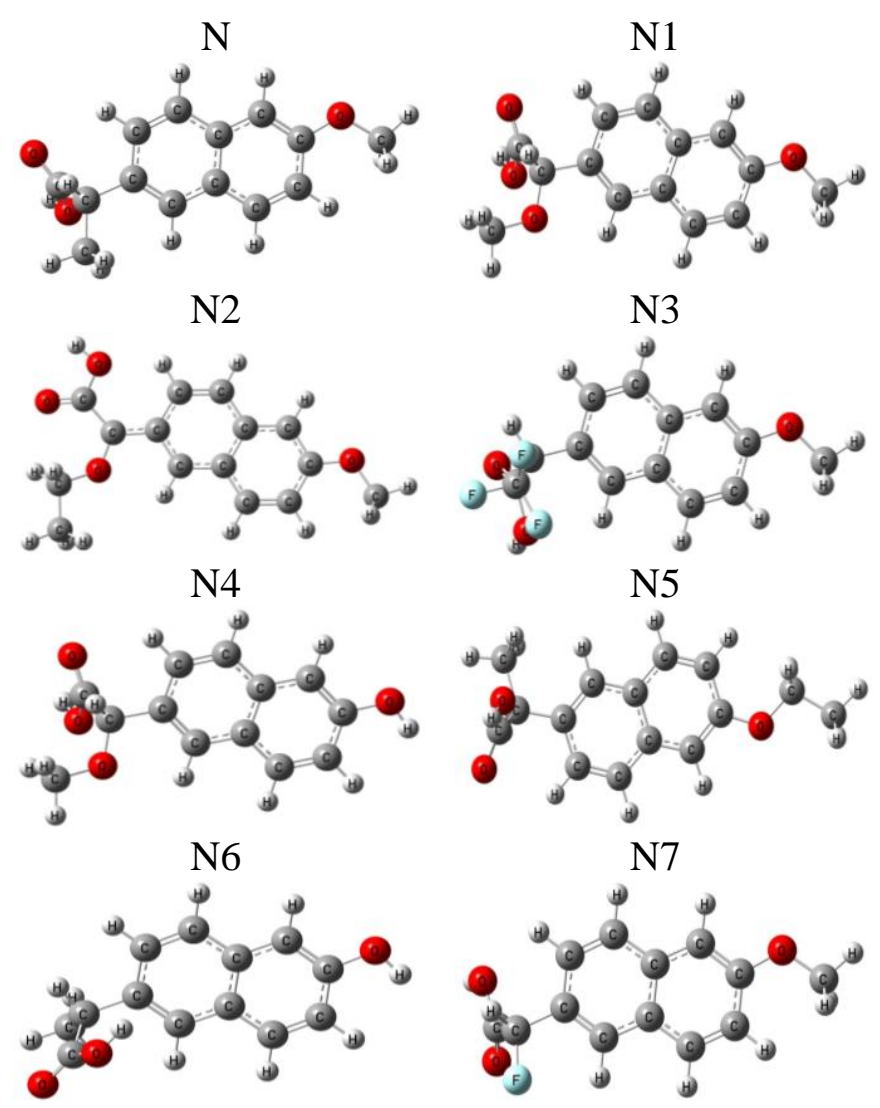

Fig. 2 Most stable optimized structure of all compounds. Optimized with B3LYP/6-31g (d, p)

\subsection{Molecular Docking Simulation, Analysis, and Visualization}

Three dimensional crystal structure of aspirin acetylated human cyclooxygenase-2 (PDB ID: 5F19) was retrieved in PDB format from online protein data bank (PDB) [22]. All hetero atoms and water molecules were eliminated using PyMol (version 1.3) software packages [23] . Energy minimization of the protein implemented by Swiss-Pdb viewer software (version 4.1.0) [24]. Than optimized drugs were subjected for molecular docking study against human prostaglandin synthase protein (5F19)

In computer aided drug design, binding affinity and mode(s) of ligand with target protein can predict by molecular docking simulation [25], [26]. Finally, molecular docking simulation was performed by 
PyRx software (version 0.8 ) [27] considering the protein as macromolecule and the drug as ligand. In this analysis, rigid docking was performed where, all rotatable bonds were converted into non-rotatable with the center grid box size 64.8642, 73.2984, and $57.9414 \AA$ along $\mathrm{x}, \mathrm{y}$ and $\mathrm{z}$ directions respectively. After docking, both the protein and ligand structures were saved in .pdbqt format required by Accelrys Discovery Studio (version 4.1) to analyze and visualize the docking result and search the interactions between ligands and amino acid residues of receptor protein [28].

\subsection{ADMET Analysis}

Absorption, metabolism and carcinogenicity of Naproxen and its derivatives were predicted by utilizing AdmetSAR online database [29]. SDF (Structure Data File) and SMILES (simplified molecular-input line-entry system) strings were used throughout the generation process.

\section{Results and Discussion}

\subsection{Thermodynamic Properties}

Simple and rational modifications of molecular structure significantly influence the structural properties including free energy, enthalpy, dipole moment, and electrostatic potential. Spontaneity of a reaction and stability of a product can be predicted from Gibb's free energy, enthalpy, and electronic energy [30]. Free energy is a significant criterion to represent the interaction of binding partners, where negative value favourable for spontaneous binding and interaction. Greater negative values predict better thermodynamic properties. The free energy of $\mathrm{N}$ is -767.43 Hartree, where N3 shows the highest negative value -998.88 Hartree. The addition of trifluoromethyl group, influence the free energy as well as polarity.With increasing the negative value from $\mathrm{N}$ to $\mathrm{N} 3$, hence suggesting energetically and configurationally more stable.

In drug design, improved dipole moment can enhance hydrogen bond and non-bonded interactions in drug receptor complexes, which keep an important role to increase binding affinity. Elevated level of dipole moment also improves the polar nature of a molecule [31]. The dipole moment of $\mathrm{N}$ is 3.18 Debye, where N6 (4.71 Debye) shows the highest value (Table 1). Therefore, for N6 with increased dipole moment resulted in increased binding affinity against 5F19.

Table 1 Stoichiometry, molecular weight, electronic energy $(E)$, enthalpy $(H)$, Gibb's free energy $(G)$ in Hartree, dipole moment $(\mu)$ in Debye of Naproxen and its modified derivatives

\begin{tabular}{llllll}
\hline $\begin{array}{l}\mathrm{Na} \\
\text { me }\end{array}$ & $\mathrm{M} . \mathrm{F}$ & $E$ & $H$ & $G$ & $\mu$ \\
\hline $\mathrm{N}$ & $\mathrm{C}_{14} \mathrm{H}_{14} \mathrm{O}_{3}$ & -767.37 & -767.36 & -767.43 & 3.18 \\
$\mathrm{~N} 1$ & $\mathrm{C}_{14} \mathrm{H}_{14} \mathrm{O}_{4}$ & -842.56 & -842.56 & -842.62 & 2.29 \\
$\mathrm{~N} 2$ & $\mathrm{C}_{15} \mathrm{H}_{15} \mathrm{O}_{4}$ & -881.23 & -881.23 & -881.30 & 2.83 \\
$\mathrm{~N} 3$ & $\mathrm{C}_{14} \mathrm{H}_{11} \mathrm{~F}_{3} \mathrm{O}_{3}$ & -998.10 & -998.10 & -998.88 & 3.74 \\
$\mathrm{~N} 4$ & $\mathrm{C}_{13} \mathrm{H}_{12} \mathrm{O}_{4}$ & -803.28 & -803.28 & -803.34 & 2.47 \\
$\mathrm{~N} 5$ & $\mathrm{C}_{15} \mathrm{H}_{16} \mathrm{O}_{3}$ & -806.66 & -806.66 & -806.72 & 3.21 \\
$\mathrm{~N} 6$ & $\mathrm{C}_{13} \mathrm{H}_{12} \mathrm{O}_{3}$ & -728.09 & -728.08 & -728.14 & 4.71 \\
$\mathrm{~N} 7$ & $\mathrm{C}_{13} \mathrm{H}_{11} \mathrm{FO}_{3}$ & -827.31 & -827.31 & -827.37 & 2.57 \\
\hline
\end{tabular}

\subsection{Frontier Molecular Orbital Analysis}

The HOMO and LUMO energies, gap, hardness, softness, chemical potential, electronegativity and electrophilic index of all drugs are presented in Table 2. The electronic absorption relates to the transition from the ground to the first excited state and mainly described by one electron excitation from HOMO to LUMO [32]. From frontier molecular orbital theory, energies of HOMO and LUMO play an important role in chemical reactivity. The HOMO-LUMO gap is related to the chemical hardness, softness, chemical potential and electrophilic index of a molecule [18]-[33]. Large HOMO-LUMO gap is responsible for high kinetic stability and low chemical reactivity. On the other hand, small HOMO-LUMO gap is important for low chemical stability, because addition of electrons to a high-lying LUMO and/or removal of electrons from a low-lying HOMO is energetically favourable in any potential reaction. HOMO-LUMO gap as well as hardness, and softness were calculated for all the drugs (Table 2). In current analysis, $\mathrm{N}$ shows the HOMO-LUMO gap (3.04 eV), where N2 shows lowest energy gap with highest softness $(0.97 \mathrm{eV})$, which may contribute to show higher chemical activity and polarizibility than others.

Table 2 Energy (eV) of HOMO, LUMO, Gap, hardness and softness of all compounds

\begin{tabular}{cccccc}
\hline Name & $\varepsilon$ HOMO & $\varepsilon$ LUMO & Gap & Hardness & Softness \\
\hline N & -8.28 & -5.24 & 3.04 & 1.52 & 0.66 \\
N1 & -8.26 & -5.28 & 2.98 & 1.49 & 0.67 \\
N2 & -8.45 & -6.40 & 2.05 & 1.02 & 0.97 \\
N3 & -8.26 & -5.30 & 2.96 & 1.48 & 0.67 \\
N4 & -5.51 & -0.96 & 4.55 & 2.27 & 0.44 \\
N5 & -8.26 & -5.28 & 2.98 & 1.49 & 0.67 \\
N6 & -5.88 & -1.41 & 4.47 & 2.24 & 0.45 \\
N7 & -5.59 & -1.13 & 4.46 & 2.23 & 0.45 \\
\hline
\end{tabular}




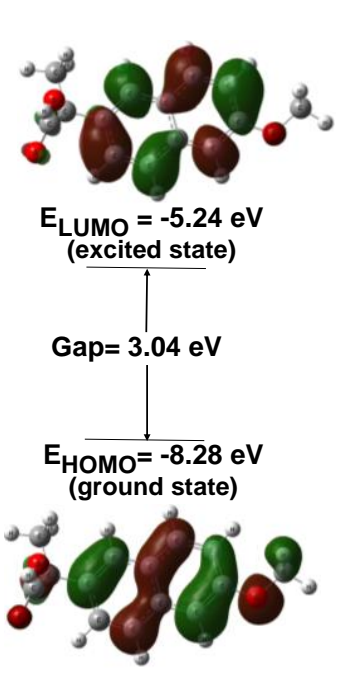

N

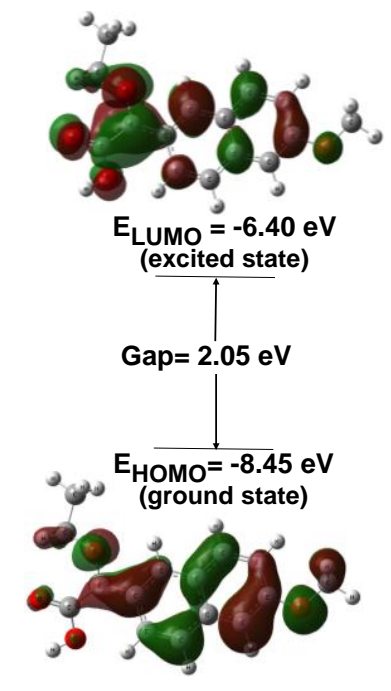

N2
Fig. 3 Frontier molecular orbital and related energy of Naproxen $(\mathrm{N})$ and $\mathrm{N} 2$

\subsection{Molecular Electrostatic Potential Analysis}

Electrostatic potential (ESP) was calculated to forecast the reactive sites for electrophilic and nucleophilic attack of all optimized structures. It also helps to interpret biological recognition process and hydrogen bonding interaction [34]. Red colour represent maximum negative area which favourable site for electrophilic attack, blue colour indicate the maximum positive area which favourable site for nucleophilic attack and green colour represent zero potential area. ESP displays molecular size, shape as well as positive, negative and neutral electrostatic potential regions simultaneously in terms of colour grading. From ESP map, region having the negative potential are over electronegative atom (oxygen atoms) and having positive potential are over hydrogen atoms. Here, the maximum negative potentiality of $\mathbf{N} 2$ molecule is -0.3782 a.u. (deepest red) for oxygen atoms and the highest positive region localized on the hydrogen atoms of N6 have value +0.2017 a.u. (deepest blue, Fig. 4)
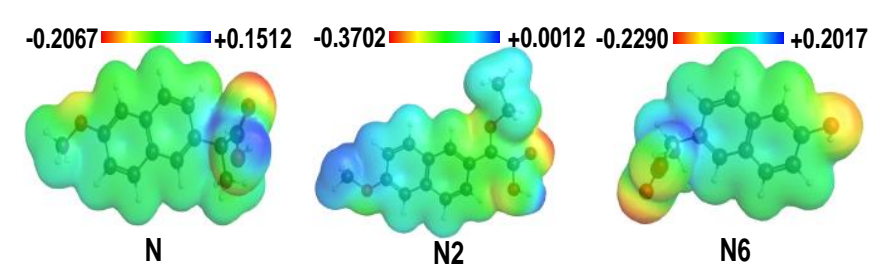

Fig.4 Molecular electrostatic potential map of Naproxen (N), N2, and N6

\subsection{Binding Affinity and Interactions of} Naproxen and its Analogues with 5F19
Binding properties of all compounds as prostaglandin inhibitor investigated by molecular docking calculation by PyRx software. Binding affinities and ligand-protein interactions are summarized in Table 3. Greater negative values of binding affinity indicate stronger binding between drugs and the receptor protein. Strong hydrogen bonding is the most significant contributing factor in increasing binding affinity of drugs with the receptor. Non-covalent interactions such as hydrogen bond, halogen bond and hydrophobic interaction are involved in the binding of examined drugs. Among various factors, hydrogen bonding is the one which can affect selectivity of nucleotide incorporation by a DNA polymerase. Recently, it is mentioned that, hydrogen bond of $<2.3 \AA$ are able to increase the binding affinity by several magnitude [35] and halogen bonds have almost similar importance as hydrogen bond in chemical and biological system [36]. The binding affinity of Naproxen is $-9.2 \mathrm{kcal} / \mathrm{mol}$ where, N3, N5, N6, and N7 have considerably increased to $-9.4,-9.5,-9.5$, and $-9.4 \mathrm{kcal} / \mathrm{mol}$ respectively. Decreased binding affinity found in case of $\mathrm{N} 1(-9.1 \mathrm{kcal} / \mathrm{mol}), \mathrm{N} 2(-8.9$ $\mathrm{kcal} / \mathrm{mol})$ and N4 (-8.8 $\mathrm{kcal} / \mathrm{mol})$. Significant hydrogen and halogen bonding observed in N3, not only contributes in increasing binding affinity but also increase binding speciality.

Except conventional Hydrogen bonds some weak intermolecular interactions such as $\mathrm{CH} / \pi, \mathrm{OH} / \pi$, $\mathrm{CH} / \mathrm{O}$ are observed for all derivatives. In derivative $\mathrm{N} 6, \mathrm{CH} / \pi$ is mostly driven by leucine and valine also small interaction happen between derivative N6 and tyrosine due to $-\mathrm{CH}_{3}$ group at $\mathrm{X}$ position with that $\pi$ electron of tyrosine. On the other hand, in N3 apart from leucine interactions, phenylalanine interactions also observed in multiple cases, this is owing to $-\mathrm{CF}_{3}$ group at $\mathrm{X}$-position and $-\mathrm{CH}_{3}$ group at $\mathrm{Y}$-position to that with phenyl alanine and so on. Also within shorter intermolecular distance, small interaction observed for alanine due to $\mathrm{CH} / \pi$ interaction between $-\mathrm{CH}_{3}$ group of alanine and $\pi$ electron of naphthalene moiety. Shorter intermolecular distance of alanine revealing that smaller the size more possibilities of approaching together. From molecular docking analysis, the major and common residues of $\mathrm{PGH} 2$ active site like Leu531, Gly526, Phe529, and Val349 form different significant interactions with the ligands. Another important residue Gly526, which form Amide-pi stacked with prostaglandin inhibitor. In addition, Leu531 form most important conventional hydrogen bond in almost every compound. In N3, Phe209 
form a Pi-pi stacked interaction and some halogen bonds are observed.

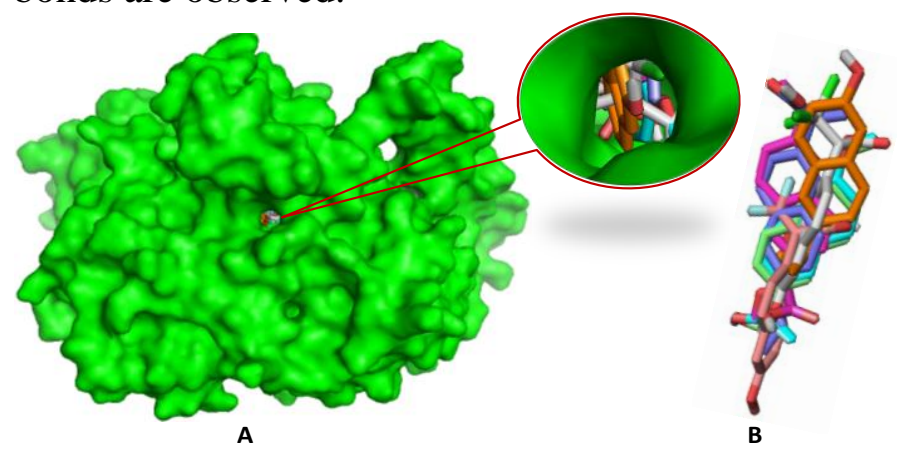

Fig. 5 (A) Docked conformation of all structures at inhibition bounding site of 5F19 (B). Superimposed view of all compounds after rigid docking

Table 3 Binding energy ( $\mathrm{kcal} / \mathrm{mol}$ ) and nonbonding interaction of Naproxen derivatives

\begin{tabular}{|c|c|c|c|c|}
\hline Name & $\begin{array}{c}\text { Binding } \\
\text { energy }\end{array}$ & $\begin{array}{c}\text { Residues in } \\
\text { contact }\end{array}$ & $\begin{array}{c}\text { Interaction } \\
\text { types }\end{array}$ & $\begin{array}{c}\text { Distance } \\
(\AA)\end{array}$ \\
\hline \multirow{14}{*}{$\mathrm{N}$} & \multirow{14}{*}{-9.2} & Leu531 & $\mathrm{H}$ & 2.84842 \\
\hline & & Leu531 & $\mathrm{H}$ & 2.64688 \\
\hline & & Gly533 & $\mathrm{H}$ & 2.94241 \\
\hline & & Leu534 & $\mathrm{H}$ & 2.40083 \\
\hline & & Phe529 & $\mathrm{H}$ & 1.91775 \\
\hline & & Met522 & $\mathrm{C}$ & 2.68760 \\
\hline & & Phe529 & PA & 3.96656 \\
\hline & & Gly526 & Aps & 4.76856 \\
\hline & & Gly526 & Aps & 3.77674 \\
\hline & & Phe205 & Pal & 4.58970 \\
\hline & & Phe209 & Pal & 4.82294 \\
\hline & & Phe381 & Pal & 5.13270 \\
\hline & & Val349 & Pal & 5.23448 \\
\hline & & Ala527 & Pal & 4.92957 \\
\hline \multirow{10}{*}{ N1 } & \multirow{10}{*}{-9.1} & Leu531 & $\mathrm{H}$ & 2.07685 \\
\hline & & Phe529 & $\mathrm{C}$ & 2.66983 \\
\hline & & Phe529 & $\mathrm{C}$ & 2.95925 \\
\hline & & Gly526 & Aps & 4.15831 \\
\hline & & Gly526 & Aps & 4.53980 \\
\hline & & Val349 & Pal & 4.99488 \\
\hline & & Ala527 & Pal & 5.05337 \\
\hline & & Val349 & Pal & 4.11982 \\
\hline & & Ala527 & Pal & 3.63944 \\
\hline & & Leu531 & Pal & 5.26761 \\
\hline \multirow{9}{*}{ N2 } & \multirow{9}{*}{-8.9} & Arg44 & $\mathrm{C}$ & 2.18583 \\
\hline & & Cys47 & $\mathrm{H}$ & 3.05240 \\
\hline & & Leu152 & A & 5.15650 \\
\hline & & Val46 & Pal & 5.27430 \\
\hline & & Cys47 & Pal & 5.35972 \\
\hline & & Pro153 & Pal & 3.98289 \\
\hline & & Cys36 & Pal & 4.69579 \\
\hline & & Cys47 & Pal & 4.32385 \\
\hline & & Pro153 & Pal & 4.61961 \\
\hline \multirow{9}{*}{ N3 } & \multirow{9}{*}{-9.4} & Leu531 & $\mathrm{H}$ & 2.77127 \\
\hline & & Leu531 & $\mathrm{H}$ & 2.77968 \\
\hline & & Ala527 & $\mathrm{C}$ & 1.98639 \\
\hline & & Gly526 & $X$ & 3.43868 \\
\hline & & Ala527 & $X$ & 2.91731 \\
\hline & & Phe529 & $X$ & 3.58353 \\
\hline & & Leu531 & $\mathrm{PC}$ & 4.52429 \\
\hline & & Phe209 & PPS & 5.12545 \\
\hline & & Leu534 & Pal & 4.51457 \\
\hline
\end{tabular}

\begin{tabular}{|c|c|c|c|c|}
\hline & & Leu534 & Pal & 4.38603 \\
\hline \multirow{6}{*}{ N4 } & \multirow{6}{*}{-8.8} & Phe529 & $\mathrm{H}$ & 2.51967 \\
\hline & & Val523 & $\mathrm{C}$ & 2.29382 \\
\hline & & Met522 & $\mathrm{C}$ & 2.59234 \\
\hline & & Gly526 & Aps & 4.48303 \\
\hline & & Gly526 & Aps & 4.31877 \\
\hline & & Val349 & $\mathrm{Pal}$ & 5.11530 \\
\hline \multirow{11}{*}{ N5 } & \multirow{11}{*}{-9.5} & Val349 & $\mathrm{H}$ & 2.42553 \\
\hline & & Ser353 & $\mathrm{C}$ & 2.51326 \\
\hline & & Phe529 & PA & 4.47861 \\
\hline & & Val523 & A & 3.80360 \\
\hline & & Leu534 & $\mathrm{A}$ & 4.06916 \\
\hline & & Phe205 & Pal & 4.82581 \\
\hline & & Phe209 & Pal & 4.95764 \\
\hline & & Val349 & Pal & 4.00498 \\
\hline & & Ala527 & Pal & 3.98747 \\
\hline & & Leu531 & Pal & 5.25001 \\
\hline & & Val349 & Pal & 4.77254 \\
\hline \multirow{11}{*}{ N6 } & \multirow{11}{*}{-9.5} & Leu531 & $\mathrm{H}$ & 2.84166 \\
\hline & & Leu531 & $\mathrm{H}$ & 1.99440 \\
\hline & & Gly526 & $\mathrm{H}$ & 2.78840 \\
\hline & & Val344 & A & 5.39467 \\
\hline & & Val349 & A & 4.88298 \\
\hline & & Tyr348 & Pal & 4.85973 \\
\hline & & Val349 & Pal & 5.03362 \\
\hline & & Leu352 & Pal & 4.95907 \\
\hline & & Val349 & Pal & 4.93668 \\
\hline & & Leu352 & Pal & 4.20127 \\
\hline & & Val523 & $\mathrm{Pal}$ & 5.14017 \\
\hline \multirow{9}{*}{ N7 } & \multirow{9}{*}{-9.4} & Leu531 & $\mathrm{H}$ & 2.60980 \\
\hline & & Phe529 & $\mathrm{H}$ & 2.81740 \\
\hline & & Met522 & $\mathrm{C}$ & 2.69700 \\
\hline & & Leu531 & $\mathrm{PC}$ & 3.04018 \\
\hline & & Phe529 & PA & 3.92486 \\
\hline & & Phe529 & PA & 4.90272 \\
\hline & & Gly526 & Aps & 3.75493 \\
\hline & & Val349 & $\mathrm{Pal}$ & 5.29136 \\
\hline & & Ala527 & Pal & 4.98871 \\
\hline
\end{tabular}

$\mathrm{H}=$ Conventional hydrogen bond, $\mathrm{C}=$ Carbon hydrogen bond, $\mathrm{A}=$ Alkyl, $\mathrm{PA}=\mathrm{Pi}$-anion, $\mathrm{PC}=\mathrm{Pi}-$ cation, $\mathrm{Pal}=\mathrm{Pi}$-alkyl, $\mathrm{PPS}=\mathrm{Pi}$-pi stacked, Aps $=$ Amide-pi stacked, $\mathrm{X}=$ Halogen bond

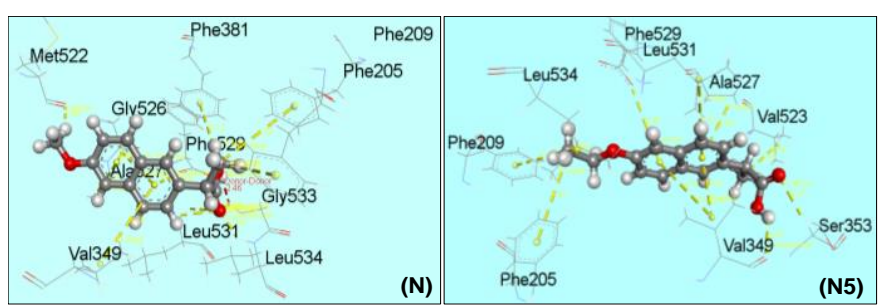

Fig.6 Nonbonding interactions Naproxen $(\mathrm{N})$ and N5 with 5F19 generated by Discovery Studio

\subsection{ADMET Analysis}

From AdmetSAR calculation (Table 4), all the drugs exhibit positive result for blood brain barrier (BBB) criteria, predicting that can pass through the $\mathrm{BBB}$ and non-carcinogenic in nature. $\mathrm{N}, \mathrm{N} 1$, and N3 show II category acute oral toxicity (AOT) and the remaining molecules show III category acute oral toxicity. So, all the compounds (except N1 and N3) 
are relatively harmless than Naproxen $(\mathrm{N})$ for oral administration. All drugs are P-glycoprotein noninhibitor, where inhibition can interrupt the absorption, permeability and retention of the drugs [37]. Moreover, most of the analogues show improved human intestinal absorption (HIA) value than N. However, all the drugs show weak inhibitory feature for human ether-a-go-go-related gene (hERG) which can lead to long QT syndrome [38], so further more study of this aspect is necessary.

Table 4 Selected pharmacokinetic parameters of Naproxen and its derivatives (Probability values related to each of the parameters are given in the parenthesis)

\begin{tabular}{ccccccc}
\hline $\begin{array}{c}\mathrm{Nam} \\
\mathrm{e}\end{array}$ & $\mathrm{BBB}$ & $\mathrm{HIA}$ & $\mathrm{PGI}$ & hERG & Carcinogen & AOT \\
\hline $\mathrm{N}$ & $+(0.69)$ & $+(0.99)$ & $\mathrm{NI}(0.87)$ & $\mathrm{WI}(0.96)$ & $\mathrm{NC}(0.87)$ & $\mathrm{II}$ \\
$\mathrm{N} 1$ & $+(0.64)$ & $+(0.98)$ & $\mathrm{NI}(0.80)$ & $\mathrm{WI}(0.98)$ & $\mathrm{NC}(0.89)$ & $\mathrm{II}[5]$ \\
$\mathrm{N} 2$ & $+(0.60)$ & $+(0.98)$ & $\mathrm{NI}(0.78)$ & $\mathrm{WI}(0.98)$ & $\mathrm{NC}(0.88)$ & $\mathrm{III}$ \\
$\mathrm{N} 3$ & $+(0.87)$ & $+(1.00)$ & $\mathrm{NI}(0.88)$ & $\mathrm{WI}(0.97)$ & $\mathrm{NC}(0.84)$ & $\mathrm{II}$ \\
$\mathrm{N} 4$ & $+(0.63)$ & $+(0.97)$ & $\mathrm{NI}(0.89)$ & $\mathrm{WI}(0.98)$ & $\mathrm{NC}(0.92)$ & $\mathrm{III}$ \\
$\mathrm{N} 5$ & $+(0.74)$ & $+(1.00)$ & $\mathrm{NI}(0.79)$ & $\mathrm{WI}(0.96)$ & $\mathrm{NC}(0.78)$ & $\mathrm{III}[6]$ \\
$\mathrm{N} 6$ & $+(0.55)$ & $+(0.99)$ & $\mathrm{NI}(0.97)$ & $\mathrm{WI}(0.95)$ & $\mathrm{NC}(0.86)$ & $\mathrm{III}$ \\
$\mathrm{N} 7$ & $+(0.83)$ & $+(1.00)$ & $\mathrm{NI}(0.88)$ & $\mathrm{WI}(0.97)$ & $\mathrm{NC}(0.85)$ & $\mathrm{III}$
\end{tabular}

$P G I=$ P-glycoprotein inhibitor, $N I=$ Non-inhibitor, $N C=$ Noncarcinogenic, $W I=$ Weak -inhibitor

\section{Conclusion}

Based on current studies, seven analogues of Naproxen have been studied for the exploring of molecular interaction and binding affinity with prostaglandin $\mathrm{H} 2$ ( $\mathrm{PGH} 2$ ) synthase protein $5 \mathrm{~F} 19$. From quantum calculation, all the compounds are thermally stable and most of the analogues show lower HOMO-LUMO gap and higher softness than parent drug $(\mathbf{N})$. From molecular docking result, strong binding affinity is found for N5-5F19, and N6-5F19complexes with significant interactions. Pharmacokinetic result predicts all drugs are noncarcinogenic and most of them (N2, N5, N6, and N7) relatively harmless than Naproxen for oral administration. Considering present investigation, N3, N5, N6, and N7 can be potent new possible candidate for better performance.

Acknowledgement $\mathrm{We}$ are thankful to Amrin Ahsan, Department of Chemistry, University of Chittagong, for her support during optimization.

\section{References}

[1] R.N. Brogden, R.M. Finder, P.R. Sawyer, T.M. Speight, G.S. Avery, Naproxen: A Review of its Pharmacological Properties and Therapeutic Efficacy and Use, Drugs. 9 (1975) 326-363. doi:10.2165/00003495-197509050-00002.

[2] K.C. Duggan, M.J. Walters, J. Musee, J.M. Harp, J.R. Kiefer, J.A. Oates, et al., Molecular basis for cyclooxygenase inhibition by the non-steroidal antiinflammatory drug, naproxen, Journal of Biological Chemistry. (2010) jbc-M110.

[3] L.J.I.I. ROBERTS, . Analgesic-Antipyretic and Antiinflammatory agents and drugs employed in the treatment of gout, Goodman and Gilman's the Pharmacological Basis of Therapeutics. (2001).

[4] V.R. Shanbhag, A.M. Crider, R. Gokhale, A. Harpalani, R.M. Dick, Ester and amide prodrugs of ibuprofen and naproxen: Synthesis, anti-inflammatory activity, and gastrointestinal toxicity, Journal of Pharmaceutical Sciences. 81 (n.d.) 149-154. doi:10.1002/jps.2600810210.

S.E. Nissen, N.D. Yeomans, D.H. Solomon, T.F. Lüscher, P. Libby, M.E. Husni, et al., Cardiovascular safety of celecoxib, naproxen, or ibuprofen for arthritis, New England Journal of Medicine. 375 (2016) 25192529.

W.-F. Huang, F.-Y. Hsiao, Y.-W. Wen, Y.-W. Tsai, Cardiovascular events associated with the use of four nonselective NSAIDs (Etodolac, Nabumetone, Ibuprofen, or Naproxen) Versus a Cyclooxygenase-2 Inhibitor (Celecoxib): A population-based analysis in taiwanese adults, Clinical Therapeutics. 28 (2006) 1827-1836.

doi:https://doi.org/10.1016/j.clinthera.2006.11.009.

[7] S. Aktar, M.F. Khan, M.M. Rahman, M.A. Rashid, Computational Study of Geometry, Polarizability, Hyperpolarizability and Molecular Docking Studies of Naproxen, Dhaka University Journal of Pharmaceutical Sciences. 15 (2016) 37-45.

[8] O.M. Laudanno, J.A. Cesolari, J. Esnarriaga, P. San Miguel, O.A. Bedini, In vivo selectivity of nonsteroidal antiinflammatory drugs and gastrointestinal ulcers in rats, Digestive Diseases and Sciences. 45 (2000) 13591365.

[9] E. Marco-Urrea, M. Pérez-Trujillo, P. Blánquez, T. Vicent, G. Caminal, Biodegradation of the analgesic naproxen by Trametes versicolor and identification of intermediates using HPLC-DAD-MS and NMR, Bioresource Technology. 101 (2010) 2159-2166.

[10] M. DellaGreca, M. Brigante, M. Isidori, A. Nardelli, L. Previtera, M. Rubino, et al., Phototransformation and ecotoxicity of the drug Naproxen-Na, Environmental Chemistry Letters. 1 (2003) 237-241.

[11] L. Juillerat-Jeanneret, F. Schmitt, Chemical modification of therapeutic drugs or drug vector systems to achieve targeted therapy: looking for the grail, Medicinal Research Reviews. 27 (2007) 574590.

[12] M.P. Gleeson, D. Gleeson, QM/MM Calculations in Drug Discovery: A Useful Method for Studying Binding Phenomena?, Journal of Chemical Information and Modeling. 49 (2009) 670-677. doi:10.1021/ci800419j.

[13] H.E. Pence, A. Williams, ChemSpider: An Online 
Chemical Information Resource, Journal of Chemical $\begin{array}{llll}\text { Education. } & 87 & \text { (2010) }\end{array}$ doi:10.1021/ed100697w.

[14] R.A. Gaussian09, 1, MJ Frisch, GW Trucks, HB Schlegel, GE Scuseria, MA Robb, JR Cheeseman, G. Scalmani, V. Barone, B. Mennucci, GA Petersson et al., Gaussian, Inc, Wallingford CT. (2009).

[15] A.D. Becke, Density-functional exchange-energy approximation with correct asymptotic behavior, Phys Rev A. $38 \quad$ (1988) 3098-3100. doi:10.1103/PhysRevA.38.3098.

[16] C. Lee, W. Yang, R.G. Parr, Development of the ColleSalvetti correlation-energy formula into a functional of the electron density, Phys Rev B. 37 (1988) 785-789. doi:10.1103/PhysRevB.37.785.

[17] H. Kruse, L. Goerigk, S. Grimme, Why the Standard B3LYP/6-31G* Model Chemistry Should Not Be Used in DFT Calculations of Molecular Thermochemistry: Understanding and Correcting the Problem, The Journal of Organic Chemistry. 77 (2012) 1082410834. doi:10.1021/jo302156p.

[18] F. Azam, N.H. Alabdullah, H.M. Ehmedat, A.R. Abulifa, I. Taban, S. Upadhyayula, NSAIDs as potential treatment option for preventing amyloid $\beta$ toxicity in Alzheimer's disease: an investigation by docking, molecular dynamics, and DFT studies, Journal of Biomolecular Structure and Dynamics. (2017) 1-19.

[19] J.-L. Calais, Density-functional theory of atoms and molecules. R.G. Parr and W. Yang, Oxford University Press, New York, Oxford, 1989. IX + 333 pp. Price $£ 45.00$, International Journal of Quantum Chemistry. 47 (1993) 101. doi:10.1002/qua.560470107.

[20] R.G. Pearson, The HSAB Principle - more quantitative aspects, Inorganica Chimica Acta. 240 (1995) 93-98. doi:http://dx.doi.org/10.1016/00201693(95)04648-8.

[21] R.G. Pearson, Absolute electronegativity and hardness correlated with molecular orbital theory, Proceedings of the National Academy of Sciences . 83 (1986) 8440-8441.

http://www.pnas.org/content/83/22/8440.abstract.

[22] M.J. Lucido, B.J. Orlando, A.J. Vecchio, M.G. Malkowski, Crystal Structure of Aspirin-Acetylated Human Cyclooxygenase-2: Insight into the Formation of Products with Reversed Stereochemistry, Biochemistry. $55 \quad$ (2016) 1226-1238. doi:10.1021/acs.biochem.5b01378.

[23] W.L. DELANO, The PyMOL Molecular Graphics System. De-Lano Scientific, San Carlos, CA, USA, Http://Wwwpymolorg.

(2002). http://ci.nii.ac.jp/naid/10025409089/en/.

[24] N. Guex, M.C. Peitsch, SWISS-MODEL and the Swiss-Pdb Viewer: An environment for comparative protein modeling, ELECTROPHORESIS. 18 (1997) 2714-2723. doi:10.1002/elps.1150181505.

[25] D. Seeliger, B.L. De Groot, Conformational transitions upon ligand binding: holo-structure prediction from apo conformations, PLoS Computational Biology. 6 (2010) e1000634.

[26] G.M. Morris, M. Lim-Wilby, Molecular Docking, in: A. Kukol (Ed.), Molecular Modeling of Proteins, Humana Press, Totowa, NJ, 2008: pp. 365-382. doi:10.1007/978-1-59745-177-2_19.

[27] S. Dallakyan, A.J. Olson, Small-Molecule Library
Screening by Docking with PyRx, in: J.E. Hempel, C.H. Williams, C.C. Hong (Eds.), Chemical Biology: Methods and Protocols, Springer New York, New York, NY, 2015: pp. 243-250. doi:10.1007/978-14939-2269-7_19.

[28] A.D.S. Version, 4.0, Accelrys, San Diego, USA, (2017).

[29] F. Cheng, W. Li, Y. Zhou, J. Shen, Z. Wu, G. Liu, et al., admetSAR: A Comprehensive Source and Free Tool for Assessment of Chemical ADMET Properties, Journal of Chemical Information and Modeling. 52 (2012) 3099-3105. doi:10.1021/ci300367a.

[30] N. Cohen, S.W. Benson, Estimation of heats of formation of organic compounds by additivity methods, Chemical Reviews. 93 (1993) 2419-2438.

[31] E.J. Lien, Z.-R. Guo, R.-L. Li, C.-T. Su, Use of dipole moment as a parameter in drug-receptor interaction and quantitative structure-activity relationship studies, Journal of Pharmaceutical Sciences. 71 (1982) 641655. doi:10.1002/jps.2600710611.

[32] S. Saravanan, V. Balachandran, Quantum chemical studies, natural bond orbital analysis and thermodynamic function of 2, 5dichlorophenylisocyanate, Spectrochimica Acta Part A: Molecular and Biomolecular Spectroscopy. 120 (2014) 351-364.

[33] R.G. Parr, Z. Zhou, Absolute hardness: unifying concept for identifying shells and subshells in nuclei, atoms, molecules, and metallic clusters, Accounts of Chemical Research. 26 (1993) 256-258. doi:10.1021/ar00029a005.

[34] P. Politzer, J.S. Murray, Molecular electrostatic potentials and chemical reactivity, Reviews in Computational Chemistry. (1991) 273-312.

[35] R.C. Wade, P.J. Goodford, The role of hydrogen-bonds in drug binding, Progress in Clinical and Biological Research. $289 \quad$ (1989) 433-444. http://europepmc.org/abstract/MED/2726808.

[36] M.G. Sarwar, D. Ajami, G. Theodorakopoulos, I.D. Petsalakis, J. Rebek, Amplified halogen bonding in a small space, Journal of the American Chemical Society. $135 \quad$ (2013) 13672-13675. doi:10.1021/ja407815t.

[37] M.L. Amin, P-glycoprotein inhibition for optimal drug delivery, Drug Target Insights. 2013 (2013) 27-34. doi:10.4137/DTI.S12519.

[38] M.C. Sanguinetti, M. Tristani-Firouzi, hERG potassium channels and cardiac arrhythmia, Nature. 440 (2006) 463-469.

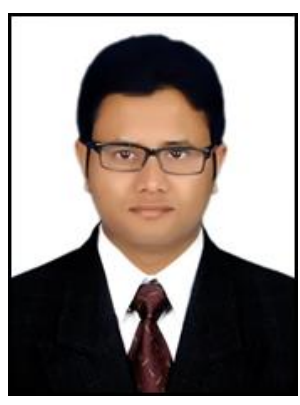

Moniruzzaman was born in $15^{\text {th }}$ November 1992 in Bangladesh. He was graduated (M.S) in Inorganic Chemistry, from University of Chittagong, Bangladesh in 2016. Now, he is purchasing his $2^{\text {nd }}$ graduation (M. Eng) in Applied Chemistry and Biochemical Engineering, from Shizuoka University, Japan. He worked on synthesis, characterization, biomedical evaluation, and molecular modeling of 
different Schiff base metal complexes, and chalcones. He also worked as a research fellow on computer aided drug design at The Red Green Research Centre (http://grcbd.org/). He has published four articles in $\mathrm{J}$. Mol. Struct, Polymer (MDPI), J. Coord. Chem. and Tetrahedron letter.His current research is Organocatalytic ring opening polymerization of lactide and glycolide under super critical carbon dioxide.

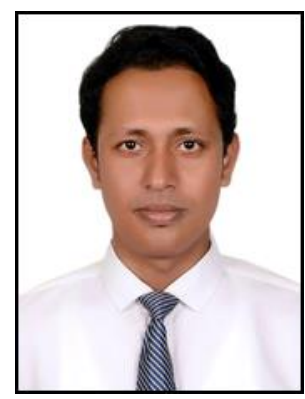

Mohammed Jabedul Hoque has completed his graduation (M.S) in Organic Chemistry in the year of 2012 from University of Chittagong, Bangladesh. $\mathrm{He}$ obtained his second degree (M.Eng) in Applied Chemistry and Biochemical Engineering from Shizuoka University, Japan and continuing doctoral program in Optoelectronics and Nanostructure science department at Shizuoka University. His current research focusing on synthesis of polymer through host guest inclusion polymrization approach for surfactant and cross link thermosating polymer applications. 